\title{
nature
}

\section{Dangers of Euro-relevance}

The European Commission has clarified as pects of its next Framew ork programme of research. A $n$ ins istence on quick delivery of socio-economic benefits threatens the programme's success.

$\mathrm{H}$ ere is relevance with a vengeance. Urged on by its member states and by the European parliament, the European Commission has at last produced a fifth Framework programme of research (FP5) that is so demanding of economic and social benefits that — reading between the lines - even some at the commission are unsure how, or even whether, it will deliver the goods.

As was clear from the long-delayed launch of the programme, in Essen last week, scientists seeking funding in FP5's four thematic programmes - life sciences, information technologies, industrial technologies, and energy and environment - will have to adopt what the commission calls a "problem-oriented approach". It will no longer be enough, as it was in $\mathrm{FP} 4$, to propose a collaborative project in applied research. This time round scientists will have to present to the commission a problem of socio-economic significance, and show that they will approach it from as many angles as are necessary to solve it.

How this will work in practice takes some explaining, as the commission attempted to do in Essen. The "problem-solving" approach, explained one speaker, involves identifying a target problem (for example, getting wet surfaces to stick to each other) with advice from end-users (dental and medical communities), then bringing together the disciplines necessary to solve the problem scientifically (chemists, structural biologists, molecular biologists ...) while integrating the problems of production from the outset (include a bioreactor specialist). A successful consortium will probably include not only scientists but also representatives of other sectors such as social science or finance, from at least two EU countries (and more credit for more countries).

This level of organization will probably put off many scientists, especially those in academia, from trying to lead a project themselves. The commission defensively argues that FP4, which established the European networks that it now wants to exploit, gives European scientists the necessary head start to create the required contacts; but it is unlikely that these contacts will suffice for the new ideas of FP5.

Some commission officials admit in private that they would not be surprised if they received a relatively low number of applications in response to the first calls for proposals, which will be issued midMarch with closing dates in early June. They expect that many scientists will prefer to watch the outcome of the first round before committing large amounts of time to preparing applications, especially when, as seems likely, they are not confident of the criteria for project eligibility. More openly, some commission officials admit that their own ideas of what specific programmes they might accept in the way of applications will only become completely clear once they see what sort of applications come in. They stated clearly in Essen that project evaluators and programme monitors will need training to operate the new approach.

EU member states demanded a radical change in the distribution of research money to improve Europe's poor performance in technology transfer. National governments can therefore take the credit if the new concept, which appears unprecedented, works. But they will deserve at least as much blame as the commission if, as seems likely, it does not.

Those concerned for the scientific future of Europe should give one cheer for the fact that a programme demonstrably successful at building networks and supporting fellowships in basic research, originally known as "Human capital and mobility" but now called "Increasing human research potential and the socio-economic knowledge base", will continue and does not insist on practical problem-solving for support. But FP5's insistence on relevance combined with its managerial demands makes it significantly more remote from the realities of Europe's science base than its predecessors. That is a cause for significant concern. In the persistent absence of strong European alternatives, all the more reason, also, for European governments to keep their national support for basic research strong.

\section{Where next on misconduct?}

\section{Tackling scientific fraud has generated its ow $\mathbf{n}$ problems, while others remain unaddressed.}

S cientists are just a little bit more morally admirable than most groups of intelligent people. That, at least, is what C. P. Snow told a meeting of the American Association for the Advancement of Science 40 years ago. Whatever the truth of that assertion then, nobody aware of the record of fabrication, falsification and plagiarism in science could say the same now. What is more, some laboratories are so internally competitive that researchers are forced to keep their work close to their chest. Where that work is also difficult to replicate because of its experimental complexity or refinement, as is most particularly the case in biomedical research, you have the breeding ground for those grand misdemeanours that have led to hundreds of thousands of dollars of research grants being wasted, and, on some occasions, to even more costly legal battles.

Science is tough and is well able to survive such troubles. But public confidence in it risks being unduly undermined and the lives of innocent individuals can be ruined. Following the lead of the United States and Scandinavia, the scientific world is confronting the situation - although the United States also provides warnings of procedures to avoid (see Briefing, pages 13-17). How to deal with accusations, how to look after the interests of the accused and of whistle-blowers, how to correct the scientific record: all of these are issues where examples have been set. High on the agenda now is to spread principles of good scientific practice.

But there is too much reliance on whistle-blowers: systematic spot checks on data and on publication records deserve more effort. Burgeoning costs in the United States require a major rethink and streamlining of the handling of misconduct cases. And there is also need for a systematic study, by surveys if necessary, of issues of credit misappropriation, exploitation and inappropriate pressures arising in laboratory hierarchies. In short, the community is making progress in fighting misconduct, but has far to go. 